\title{
ONE HUNDRED YEARS OF ZYGOTIC EMBRYO CULTURE INVESTIGATIONS
}

\author{
V. RAGHAVAN* \\ Department of Plant Biology, The Ohio State University, 1735 Neil Avenue, Columbus, OH 43210, USA
}

(Received 5 February 2003; accepted 27 February 2003; editor E. C. Pua)

\begin{abstract}
SuMmary
Isolation of zygotic embryos from seeds and their culture in a defined medium, initiated by Hannig in 1904, has proved to be a promising method to study the factors that control growth and differentiation of embryos. Using this technique, several investigations have focused on the carbohydrate and nitrogen nutrition during germination of cultured seed embryos and on the effects of plant hormones on their morphogenesis. Culture of immature embryos leads to their germination into weak seedlings, skipping the later stages of embryogenesis, by a process known as precocious germination. Progressively smaller embryos have been cultured by supplementation of the medium with coconut milk or hormonal additives or by osmotic adjustment of the medium by high concentrations of sucrose or mannitol. Although methods have not been developed for large-scale isolation and culture of zygotes, zygotes of maize isolated from embryo sacs and those obtained by in vitro fertilization have been grown in culture into full-term embryos. Embryo culture techniques are widely used to rescue embryos from seeds of wide crosses which usually abort and to overcome dormancy of recalcitrant seeds.
\end{abstract}

Key words: historical review; embryo morphogenesis; proembryo culture; zygote culture; hybrid rescue; overcoming seed dormancy.

\section{INTRODUCTION}

Embryo culture - the cultivation of zygotic embryos excised from ovules and seeds under aseptic conditions in a medium of known chemical composition - represents an important milestone in efforts to identify the requirements essential for continued growth, differentiation, and morphogenesis of embryos. The main reason for this is that the embryo culture technique allows the investigator to manipulate the embryo experimentally outside the ovule or the seed in ways that are not easy to accomplish when the embryo is enclosed in the ovule or seed. The development of the zygote into an embryo involving cell division, cell elongation, and organ differentiation depends upon the interaction between the newly formed cells, on the one hand, and the nutrient materials provided by the endosperm and the surrounding tissues of the ovule, on the other. The nature of the interactive effects modulating embryo growth is best understood by growing embryos outside the ovule or the seed in a standardized way and nurtured by exogenous nutrients. On the applied side, embryo culture has become a well-recognized and widely used method to obtain plants from wide crosses whose seeds generally abort due to failure of germination. In some types of seed, which germinate only after a period of storage and which do not respond favorably to other dormancy-breaking treatments, dormancy can be overcome by excision and culture of embryos. Over the past 100 years since its introduction, the embryo culture technique has offered a new and refined approach to characterizing embryogenesis

\footnotetext{
*Author to whom correspondence should be addressed: Email raghavan.
} $1 @$ osu.edu and related problems in plants; some of these landmark studies opened up by embryo culture are chronicled in the present paper, written to mark this anniversary of the discovery of embryo culture. Since no comprehensive coverage of the topic is intended here, references to review articles are given to enable the interested reader to access further information on the significant contributions highlighted. Periodic reviews by Rappaport (1954), Sanders and Ziebur (1963), Narayanaswami and Norstog (1964), Raghavan (1966, 1980, 1993), and Raghavan and Srivastava (1982), besides cataloging the surges in examples of successfully cultured embryos, have served to convey the refinements in the technique to culture progressively smaller embryos. For someone interested in trying his or her hand at the game, brief technical details and recipes for the media most commonly used to culture embryos of various stages of development of different plants are given in the articles by Sanders and Ziebur (1963), Raghavan (1967, 1977a), and Williams et al. (1987).

\section{The Beginning}

Although references to the importance of the embryo and its relationship to the endosperm in the genesis of the seedling are found in the literature dating back to the mid-19th century, establishment of embryo culture as an experimental tool can be dated rather precisely with the paper by Hannig (1904). Using aseptic techniques, this investigator cultured relatively mature embryos of Raphanus sativus, $R$. landra, $R$. caudatus, and Cochlearia danica (all of Brassicaceae) in a mineral salt medium 
supplemented with sucrose, and obtained transplantable seedlings. Attempts to culture embryos in the liquid extracted from ovules with a fine capillary were however unsuccessful, but they showed that a possible role of the liquid endosperm of the ovule in the nurture of embryos was very much a pervading theme in this work. Particularly interesting and conclusive seems to be the proof provided for a requirement for a high osmotic concentration in the medium for successful growth of embryos, as the latter generally failed to grow in a mineral salt medium unless supplied with a concentration of sucrose far above that required as a carbon energy source. The essentiality of a suitable nitrogen source for successful growth of embryos was another question of profound importance addressed in this work. In contrast to the abstract and general arguments found in the earlier studies on embryo growth, Hannig's paper provided quantitative data on the growth of embryos of the four species in the different media; the striking similarity in nutrient requirements for embryo growth was reflected in the frequent cross-species comparisons.

Culture method was effectively used by Brown (1906) to study the relative efficiency of various organic nitrogen compounds on the growth of excised barley (Hordeum vulgare) embryos nurtured in a mineral salt medium containing sucrose. This work showed that the amino acids, aspartic acid and glutamic acid, and the amide, asparagine, are superior nitrogen sources, causing increased dry weight and nitrogen content of cultured embryos. In other studies, the role of the storage tissues of the seed in the growth of embryos was explored by separating the latter from the endosperm or by decotylating embryos at different times after soaking seeds and planting embryos in nutrient solutions. Although the experiments confirmed the favorable effects of the storage tissues of the seed in the growth of the embryo, they were not found to be indispensable for embryo nurture (Dubard and Urbain, 1913). The relatively small amount of growth displayed by decotylated embryos of lima bean (Phaseolus lanatus) cultured in distilled water solidified with agar was, however, found to be appreciably improved by the addition of glucose or a reducing sugar-containing extract made from the cotyledons of germinated seeds (Buckner and Kastle, 1917). A function for the scutellum of graminean embryos in the absorption of nutrients was implied in a study that showed that embryos of maize (Zea mays) devoid of this organ grow somewhat feebly (Andronescu, 1919). Collectively, these investigations showed the beginnings of a fusion of embryo culture methodology and physiological principles to gain insight into the nutrient requirements and metabolism of germinating embryos.

Based on the behavior of cultured embryos belonging to Solanaceae, Linaceae, Brassicaceae, Polygonaceae, Asteraceae, Cucurbitaceae, and Poaceae, Dieterich (1924) pointed out two important generalizations which have proved to be significant in understanding the physiology of the growth of embryos. One was that the embryo grown in vitro usually skips a rest period that is observed when it is part of the intact seed, and germinates. In addition, it was found that a solid medium containing Knop's mineral salts and 2.5-5.0\% sucrose can support normal growth of embryos isolated from mature seeds, but in the same medium embryos from immature seeds tend to form malformed seedlings, omitting the regular stages in embryogenesis. This type of growth, uncovered not by preplanned scientific enquiry, but serendipitously from manipulations of the test object, came to be recognized as 'precocious germination' in embryo culture studies.

\section{Metabolic and Morphogenetic Studies}

A number of investigations using cultured embryos in the decades following the studies described above have set the stage to delve more deeply into the metabolism and physiology of embryos. The superiority of sucrose as a carbon energy source for cultured embryos is now firmly established and rarely has any other carbohydrate been as successful. At the morphogenetic level, addition of sucrose to the medium has been shown to promote root growth (Rietsema et al., 1953; Ozsan and Cameron, 1963; del Rosario and de Guzman, 1976), or the growth of both root and shoot primordia (Augsten, 1956; Buffard-Morel, 1968) of cultured embryos of a variety of plants. Based on studies involving supplementation of the medium with various nitrogen compounds, a few generalizations about the amino acid metabolism of cultured embryos have also emerged. One is that embryos are able to grow moderately well in a medium utilizing nitrate or ammonium salts as the sole source of nitrogen. Secondly, the amide glutamine serves as an efficient source of nitrogen for the growth in culture of embryos of a number of plants (Rijven, 1956; Matsubara, 1964). Thirdly, mutual antagonism and synergism has been shown to exist between different amino acids in the growth of embryos (Sanders and Burkholder, 1948; Harris, 1956; Bright et al., 1978; Green and Donovan, 1980).

Following the discovery of plant hormones, especially the auxins, gibberellins and cytokinins, there has been much effort to study their effects on the growth and morphogenesis of cultured embryos. From a review of the results of these investigations (Raghavan, 1976, 1980; Raghavan and Srivastava, 1982), it appears that although the addition of hormones modifies the growth of cultured embryos, there is no evidence to demonstrate the need for a specific hormone for the overall growth of embryos of a wide range of plants. Regarding the effects of hormones on the growth of embryonic organs, they are quite similar to those displayed by the corresponding organs of the seedling. A recent work has, however, implied that polar auxin transport is involved in modulating cell divisions in a localized region of the globular embryo where cotyledons arise. This is based on the observation that treatment of cultured globular embryos of Brassica juncea with auxin transport inhibitors leads to the formation of a ring-like structure around the shoot apex, akin to fused cotyledons, instead of two separate cotyledons. Since the effect is specific to the globular embryo, it has been suggested that auxin signaling is an integral part of the mechanism that directs localized cell divisions in the embryo to form cotyledons (Liu et al., 1993). The involvement of auxins, especially of 2,4-dichlorophenoxyacetic acid (2,4-D), in the production of callus on cultured embryos is now firmly established. With the demonstration that the callus formed on embryos of Cuscuta reflexa grown in a medium containing casein hydrolyzate and indoleacetic acid (IAA) regenerates adventive embryos (Maheshwari and Baldev, 1961), considerable interest, which is continued even to this day, was generated in the production of somatic embryos from various plants with seed embryos as the starting material.

In attempts made during this period to control precocious germination of embryos, recourse was made to manipulation of the culture medium. Thus, it was found that supplementation of the usual agar medium containing mineral salts and a moderate level of sucrose with casein hydrolyzate, tomato juice, or other natural plant 
extracts (Kent and Brink, 1947), high concentrations of sucrose or mannitol (Ziebur et al., 1950), or the plant hormone abscisic acid (ABA) (Norstog, 1972) forestalls precocious germination and prolongs embryogenic growth of immature barley embryos. These results led to the logical view that nutrient substances of the medium, its osmolarity or its hormonal balance might play a role in the normal growth of cultured embryos and in the control of precocious germination.

Progress made by biochemical approaches in the study of precocious germination in later years has led to a greater understanding of this phenomenon, favoring a role for ABA. Ihle and Dure $(1970,1972)$ showed that culture of immature embryos of cotton (Gossypium hirsutum) triggers precocious germination as well as the development of activity of certain proteases involved in the mobilization of food reserves of cotyledons by premature translation of their relevant mRNAs; addition of an aqueous extract of the ovule or ABA to the medium halts precocious germination of immature embryos and the development of enzyme activity in them. In precociously germinating embryos of Brassica napus the synthesis of storage proteins is slowed down or inhibited, whereas in the presence of $\mathrm{ABA}$ in the medium which suppresses precocious germination, cultured embryos accumulate these proteins almost to the same extent as those growing in situ (Crouch and Sussex, 1981). As reviewed elsewhere (Raghavan, 1986a, 1997), this simple model of the role of $\mathrm{ABA}$ in curtailing precocious germination of embryos has been confirmed in many plants, raising the possibility that ABA is a natural factor that suppresses precocious germination during normal embryogenesis.

\section{Culture of Proembryos and Zygotes}

An offshoot of the culture of seed embryos practiced in much of the early work was the culture of proembryos - a term applied to embryos at developmental stages that precede cotyledon initiation. An implicit assumption in most investigations is that proembryos are heterotrophic in nature and are dependent not only upon the metabolites present in their cells, but also upon these diffusing from the endosperm and the surrounding maternal tissues. From the embryo culture perspective, this suggests that nutritional requirements for the culture of proembryos are bound to be more exacting than those for immature or mature embryos. In much of the work done up to about 1940 , only limited success was obtained in attempts to culture proembryos of selected plants in media containing IAA, amino acids, yeast extract, casein hydrolyzate, and other complex products. A breakthrough came from the work of van Overbeek et al. (1942) on the culture of embryos of Datura stramonium. This work showed that whereas torpedo-shaped and heart-shaped embryos grow in a medium enriched with vitamins (nicotinic acid, ascorbic acid, pyridoxine, and pantothenic acid) and an assortment of organic substances (adenine, glycine, and succinic acid), still smaller embryos (200-500 $\mu \mathrm{m}$ long) fail to grow or grow feebly in this medium before callusing. A dramatic recrudescence of growth occurs in the small embryos when the medium containing organic addenda is supplemented with the liquid endosperm of coconut known as coconut milk or coconut water. This was attributed to the presence of a hormonal factor, designated the 'embryo factor', which was later obtained in a pure form to promote the growth of embryos in a dilution as low as 1:19000 on a dry weight basis compared with 1:110 for the crude milk (van Overbeek et al., 1944). These studies spawned several successful attempts to culture proembryos of other plants by the use of plant extracts of endospermic or nonendospermic origin (Kent and Brink, 1947; Matsubara, 1962; Nakajima, 1962), or by using the endosperm as a nurse tissue (Stefaniak, 1987). In another work, Norstog and Smith (1963) were able to substitute for a requirement for coconut milk in the promotion of growth of undifferentiated barley embryos by a phosphate-enriched medium at $\mathrm{pH} 4.9$, fortified with glutamine and alanine $\left(400 \mathrm{mgl}^{-1}\right.$ each) as major nitrogen sources, and lesser amounts of leucine $\left(20 \mathrm{mgl}^{-1}\right)$, tyrosine, phenylalanine, cysteine, and tryptophan (all at $10 \mathrm{mgl}^{-1}$ ). Growth promotion of cultured proembryos by endosperm extracts thus appears to be mediated by specific chemical compounds.

It has been known for some time that the amorphous liquid endosperm in which the proembryo is constantly bathed has a very low (more negative) osmotic potential that subsequently decreases (becomes more negative) as the embryo matures (Ryczkowski, 1960). This has led to the view that the osmotic pressure of the medium might play a role in promoting growth of proembryos both in vitro and in vivo. Following upon the success with coconut milk as a growth adjuvant for inducing growth of proembryos of D. stramonium, it was found that a mineral salt medium fortified with $8-12 \%$ sucrose was optimal for continued growth and differentiation of globular and preheart-shaped embryos. Interestingly enough, these same embryos respond in, exactly the same way to a medium containing $2 \%$ sucrose plus enough mannitol to be isotonic with 8-12\% sucrose (Rietsema et al., 1953). Artificially increasing the osmotic concentration of the culture medium by the addition of high concentrations of sucrose or mannitol has also led to the successful culture of proembryos of other plants which did not survive even the most complex media tested; these include a widely investigated species, Capsella bursa-pastoris (Rijven, 1952), and a recent addition, wheat (Triticum aestivum) (Fischer and Neuhaus, 1995). From this it appears that sucrose functions more as an osmotic stabilizer in the medium than as a carbon energy source, although the latter role cannot be wholly discounted.

The promotion of growth of proembryos by hormonal additives in the medium is illustrated by the requirements for growth in culture of progressively smaller embryos of C. bursa-pastoris. Although heart-shaped and older embryos of this species have been routinely cultured in an inorganic liquid medium of high osmolarity secured by the addition of 12-18\% sucrose (Rijven, 1952), later work opened up the feasibility of culturing heart-shaped embryos in an agar-solidified mineral salt medium supplemented with $2 \%$ sucrose. Growth of still smaller embryos (up to about $55 \mu \mathrm{m}$ long) was secured by fortifying this medium with a balanced mixture of IAA, kinetin, and adenine sulfate (Raghavan and Torrey, 1963). Other reports of growth promotion of proembryos of Linum usitatissimum by kinetin (Prě̌ová, 1986), heart-shaped embryos of Medicago scutellata and M. sativa by IAA and benzylaminopurine (Bauchan, 1987) and proembryos of maize by zeatin or benzylaminopurine (Matthys-Rochon et al., 1998), have also appeared.

A role for the suspensor in embryo nutrition implied from morphological and cytological studies has been strengthened by investigations in which growth of the organogenetic part of the embryo severed of its connection with the suspensor was followed. From experiments using this approach, it has been found that continued growth of proembryos of Eruca sativa (Corsi, 1972), Phaseolus coccineus (Yeung and Sussex, 1979), and 
C. bursa-pastoris (Monnier, 1984) is more enhanced in the presence of an attached suspensor than in its absence. Other experiments on $P$. coccineus involving supplementation of the medium with growth hormones and determination of the growth hormone levels in the embryo and suspensor cells at specific stages of development have provided indirect evidence to show that the presumed suspensor function is due to the production of gibberellins and cytokinins (Alpi et al., 1975; Cionini et al., 1976; Lorenzi et al., 1978; Bennici and Cionini, 1979). These results provide a strong argument for the existence of hormonal gradients from the suspensor in regulating the growth of the proembryo and might serve as baseline information for formulating a medium for the culture of still smaller embryos and even of the zygote of $P$. coccineus.

With many plants, extracting proembryos and zygotes from the confines of the ovule has hindered attempts at their successful culture, but some inroads have been made with zygote culture in maize. One strategy followed is the culture of zygote- or proembryocontaining embryo sac surrounded by the nucellus with or without a block of the endosperm (Campenot et al., 1992; Mòl et al., 1993, 1995). By the use of enzyme digestion and microdissection, zygotes isolated from embryo sacs have been induced to form fertile plants by simulating typical stages of in vivo embryogenesis. The unexpected finding was that a nurse tissue of embryogenic microspores of barley was necessary for inducing continued growth and division of explanted maize zygotes (Leduc et al., 1996). The same nurse tissue culture system was used to induce the growth of zygotes extruded from embryo sacs of barley (Holm et al., 1994) and wheat (Kumlehn et al., 1998) into normal plants. Maize zygotes produced by in vitro fertilization go through embryogenic divisions and form fertile plants relatively easily in the presence of a nurse tissue constituted of cells originating from maize embryos (Kranz and Lörz, 1993). The excitement generated by the culture of zygotes extruded from the embryo sac and those generated by in vitro fertilization might seem to suggest that methodologies are at hand to culture zygotes routinely in a defined medium and study the activation of biosynthetic pathways during progressive embryogenesis. This is rather far from the truth and there is a long way ahead before this cherished hope can be realized.

\section{Applications of Embryo Culture Technique}

On the practical side, the first application of embryo culture technique came from the work of Knudson (1922), who succeeded in germinating orchid embryos into plantlets in the absence of the symbiotic fungus by growing them on a nutrient agar medium containing sucrose. In the absence of sucrose, embryos failed to develop beyond the protocorm stage. The propagation of orchids now practiced on a commercial scale in nurseries all over the world had its inception in these experiments. In most species of orchids, the embryo is extremely small in size and consists of a mass of undifferentiated cells enclosed within two fused transparent layers of cells of seed coats. Since mature orchid embryos do not show a distinction between shoot and root poles, they are analogous to globular-stage embryos of other angiosperms, but unlike the latter, subsequent development of the embryo occurs during germination. Thus, embryo culture of orchids represents in reality seed culture.

Crosses between distantly related species of plants have been slow to yield agriculturally beneficial hybrids because in the transfer of useful alien genes across interspecific or intergeneric barriers, too many deleterious genes that are difficult to eliminate are also introduced. The resulting disturbance in equilibrium between the growth of the maternal tissues, embryo, and endosperm leads to embryo lethality and seed collapse. Early in the development of embryo culture as a research tool, Laibach (1925) envisaged the immense application of the embryo culture technique in rearing viable seedlings from otherwise unsuccessful crosses. This investigator showed that progenies from crosses between Linum perenne and L. austriacum can be rescued by excising and culturing embryos before they disintegrate. Since this pioneering work, embryo culture methods have been widely used to obtain transplantable seedlings from seeds of interspecific and intergeneric crosses previously considered incapable of germination. The numerous examples in which hybrid embryo operations have been successfully mounted by embryo culture methods are reviewed elsewhere (Raghavan, 1977b, 1985, 1986b, 1994; Collins and Grosser, 1984; Williams, 1987). Although nutrient media employed to culture embryos are very varied, it can be stated as a secure generalization that hybrid embryos which collapse at early stages of development require more complex media than more developed embryos to complete growth in culture. After the embryos have grown into plantlets in vitro, they are removed from the original medium and nurtured in sterilized soil or vermiculite and grown to maturity in the greenhouse.

In breeding practice, dormancy of seeds and the slow growth of seedlings necessitate long breeding seasons. Seeds of some earlyripening fruit trees have very low viability and fail to germinate even after appropriate after-ripening treatments. It was shown that embryos excised from such seeds grow normally in vitro into healthy plants (Tukey, 1933). It has thus become possible to preserve these varieties for the development of still earlier ripening characteristics which would be of practical benefit to the breeder (Raghavan, 1976, for review). Dormant seeds fail to germinate under apparently suitable conditions of adequate moisture and oxygen supply and optimum temperature unless they are given the appropriate dormancy-breaking stimulus. Since dormancy mechanisms in most cases hinge on the inability of the enclosed embryo to grow, special interest attaches to the role of embryo culture method in overcoming this developmental block. Recognition of the need for an effective method for breaking dormancy of seeds of tall bearded Iris and obtaining flowers in a shorter period of time than normal led Randoph (1945) to study seedling production by embryo culture method. It was found that young seedlings with well-developed roots and leaves ready to be transplanted into soil could be obtained in about 2 or 3 mo. after transfer of embryos to a suitable medium. The use of embryo culture has done much to reduce the cycle from seed to flowering in Iris to less than a year, in contrast to the 2 or $3 \mathrm{yr}$ normally required. It is a matter of common observation that seeds of some of the common cereals remain dormant immediately after harvest even though the embryo is fully mature. Embryo culture might be advantageously used to raise a new generation of seedlings from such cereal grains immediately after harvest (Raghavan, 1976, for review).

\section{Conclusions}

The manipulations performed with embryos of different ages of various plants have revealed some important principles about 
control of growth and differentiation of embryos for nearly a century. As we come to the next century of use of the embryo culture technique, it seems possible to overlay this rich history with the power of genetic manipulations to reveal a new generation of concepts about angiosperm embryogenesis. In comparison with some of the other in vitro methods, embryo culture is a timeconsuming operation involving a great deal of manipulative skill. Nonetheless, in various agricultural stations around the world, embryo culture has become the choice method to obtain hybrids from wide crosses. The potential of zygote culture to transfer foreign genes in a single-step method affords hope for significant advances in the genetic engineering of plants.

\section{References}

Alpi, A.; Tognoni, F.; D'Amato, F. Growth regulator levels in embryo and suspensor of Phaseolus coccineus at two stages of development. Planta 127:153-162; 1975

Andronescu, D. I. Germination and further development of the embryo of Zea mays separated from the endosperm. Am. J. Bot. 6:443-452; 1919.

Augsten, H. Wachstumsversuche mit isolierten Weizen-Embryonen. Planta 48:24-46; 1956

Bauchan, G. R. Embryo culture of Medicago scutellata and M. sativa. Plant Cell Tiss. Organ Cult. 10:21-29; 1987.

Bennici, A.; Cionini, P. G. Cytokinins and in vitro development of Phaseolus coccineus embryos. Planta 147:27-29; 1979.

Bright, S. W. J.; Wood, E. A.; Miflin, B. J. The effect of aspartate-derived amino acids (lysine, threonine, methionine) on the growth of excised embryos of wheat and barley. Planta 139:113-117; 1978.

Brown, H. T. On the culture of the excised embryos of barley on nutrient solutions containing nitrogen in different forms. Trans. Guinness Res. Lab. 1:288-299; 1906.

Buckner, G. D.; Kastle, J. H. The growth of isolated plant embryos. J. Biol. Chem. 29:209-213; 1917.

Buffard-Morel, J. Effets du glucose, du lévulose, du maltose et du saccharose sur le développement des embryons de palmier à huile (Elaeis guineensis Jacq. Var. Dura Bec.) en culture in vitro. Compt. Rend. Acad. Sci. Paris 267D:185-188; 1968.

Campenot, M. K.; Zhang, G.; Cutler, A. J.; Cass, D. D. Zea mays embryo sacs in culture. I. Plant regeneration from 1 day after pollination embryos. Am J. Bot. 79:1368-1373; 1992

Cionini, P. G.; Bennici, A.; Alpi, A.; D'Amato, F. Suspensor, gibberellin and in vitro development of Phaseolus coccineus embryos. Planta 131:115-117; 1976.

Collins, G. B.; Grosser, J. W. Culture of embryos. In: Vasil, I. K., ed. Cell culture and somatic cell genetics of plants, vol. 1. Laboratory procedures and their applications. Orlando, FL: Academic Press; 1984: $241-257$

Corsi, G. The suspensor of Eruca sativa Miller (Cruciferae) during embryogenesis in vitro. Giorn. Bot. Ital. 106:41-54; 1972

Crouch, M. L.; Sussex, I. M. Development and storage-protein synthesis in Brassica napus L. embryos in vivo and in vitro. Planta 153:64-74; 1981.

del Rosario, A. G.; de Guzman, E. V. The growth of coconut 'makapuno' embryos in vitro as affected by mineral composition and sugar level of the medium during the liquid and solid cultures. Philipp. J. Sci. 105:215-222; 1976

Dieterich, K. Über Kultur von Embryonen ausserhalb des Samens. Flora 117:379-417; 1924

Dubard, M.; Urbain, J.-A. De l'influence de l'albumen sur le développement de l'embryonen. Compt. Rend. Acad. Sci. Paris 156:1086-1089; 1913.

Fischer, C.; Neuhaus, G. In vitro development of globular zygotic wheat embryos. Plant Cell Rep. 15:186-191; 1995.

Green, C. E.; Donovan, C. M. Effect of aspartate-derived amino acids and aminoethyl cysteine on growth of excised mature embryos of maize. Crop Sci. 20:358-362; 1980.
Hannig, E. Zur Physiologie pflanzlicher Embryonen. I. Ueber die Cultur von Cruciferen-Embryonen ausserhalb des Embryosacks. Bot. Ztg $62: 45-80 ; 1904$.

Harris, G. P. Amino acids as sources of nitrogen for the growth of isolated oat embryos. New Phytol. 55:253-268; 1956.

Holm, P. B.; Knudsen, S.; Mouritzen, P.; Negri, D.; Olsen, F. L.; Roué, C. Regeneration of fertile barley plants from mechanically isolated protoplasts of the fertilized egg cell. Plant Cell 6:531-543; 1994

Ihle, J. N.; Dure, L., III. Hormonal regulation of translation inhibition requiring RNA synthesis. Biochem. Biophys. Res. Commun. 38:995-1001; 1970

Ihle, J. N.; Dure, L. S., III. The developmental biochemistry of cotton seed embryogenesis and germination. III. Regulation of the biosynthesis of enzymes utilized in germination. J. Biol. Chem. 247:5048-5055; 1972.

Kent, N.; Brink, R. A. Growth in vitro of immature Hordeum embryos. Science 106:547-548; 1947.

Knudson, L. Nonsymbiotic germination of orchid seeds. Bot. Gaz. 73:1-25; 1922.

Kranz, E.; Lörz, H. In vitro fertilization with isolated, single gametes results in zygotic embryogenesis and fertile maize plants. Plant Cell 5:739-746; 1993.

Kumlehn, J.; Lörz, H.; Kranz, E. Differentiation of isolated wheat zygotes into embryos and normal plants. Planta 205:327-333; 1998.

Laibach, F. Das Taubwerden von Bastardsamen und künstliche Aufzucht früh absterbender Bastardembryonen. Z. Bot. 17:417-459; 1925 .

Leduc, N.; Matthys-Rochon, E.; Rougier, M.; Mogensen, L.; Holm, P.; Magnard, J. L.; Dumas, C. Isolated maize zygotes mimic in vivo embryonic development and express microinjected genes when cultured in vitro. Dev. Biol. 177:190-203; 1996.

Liu, C. M.; Xu, Z. H.; Chua, N. H. Auxin polar transport is essential for the establishment of bilateral symmetry during early plant embryogenesis. Plant Cell 5:621-630; 1993.

Lorenzi, R.; Bennici, A.; Cionini, P. G.; Alpi, A.; D'Amato, F. Embryo-suspensor relations in Phaseolus coccineus: cytokinins during seed development. Planta 143:59-62; 1978.

Maheshwari, P.; Baldev, B. Artificial production of buds from the embryos of Cuscuta reflexa. Nature 191:197-198; 1961.

Matsubara, S. Studies on a growth promoting substance, 'embryo factor', necessary for the culture of young embryos of Datura tatula in vitro. Bot. Mag. Tokyo 75:10-18; 1962.

Matsubara, S. Effect of nitrogen compounds on the growth of isolated young embryos of Datura. Bot. Mag. Tokyo 77:253-259; 1964.

Matthys-Rochon, E.; Piola, F.; le Deunff, E.; Mòl, R.; Dumas, C. In vitro development of maize immature embryos: a tool for embryogenesis analysis. J. Exp. Bot. 49:839-845; 1998.

Mòl, R.; Matthys-Rochon, E.; Dumas, C. In vitro culture of fertilized embryo sacs of maize: zygotes and two-celled proembryos can develop into plants. Planta 189:213-217; 1993.

Mòl, R.; Matthys-Rochon, E.; Dumas, C. Embryogenesis and plant regeneration from maize zygotes by in vitro culture of fertilized embryo sacs. Plant Cell Rep. 14:743-747; 1995.

Monnier, M. Survival of young immature Capsella embryos cultured in vitro. J. Plant Physiol. 115:105-113; 1984.

Nakajima, T. Physiological studies of seed development, especially embryonic growth and endosperm development. Bull. Univ. Osaka Pref. Ser. B 13:13-48; 1962.

Narayanaswami, S.; Norstog, K. Plant embryo culture. Bot. Rev. $30: 587-628 ; 1964$.

Norstog, K. Factors relating to precocious germination in cultured barley embryos. Phytomorphology 22:134-139; 1972.

Norstog, K.; Smith, J. E. Culture of small barley embryos on defined media. Science 142:1655-1656; 1963

Ozsan, M.; Cameron, J. W. Artificial culture of small Citrus embryos, and evidence against nucellar embryony in highly zygotic varieties. Proc. Am. Soc. Hort. Sci. 82:210-216; 1963.

Pretová, A. Growth of zygotic flax embryos in vitro and influence of kinetin. Plant Cell Rep. 3:210-211; 1986.

Raghavan, V. Nutrition, growth and morphogenesis of plant embryos. Biol. Rev. 41:1-58; 1966 
Raghavan, V. Plant embryo culture. In: Wilt, F. H.; Wessels, N. K., eds. Methods in developmental biology. New York: T. Y. Crowell; 1967:413-424.

Raghavan, V. Experimental embryogenesis in vascular plants. London: Academic Press; 1976:187-192.

Raghavan, V. Diets and culture media for plant embryos. In: Rechcigl, M., Jr., ed. CRC handbook series in nutrition and food. Section G: diets, culture media, food supplements, vol. IV. Culture media for cells, organs and embryos. Cleveland, OH: CRC Press; 1977a:361-413.

Raghavan, V. Applied aspects of embryo culture. In: Reinert, J.; Bajaj, Y. P. S., eds. Applied and fundamental aspects of plant cell, tissue, and organ culture. Berlin: Springer-Verlag; 1977b:375-397.

Raghavan, V. Embryo culture. In: Vasil, I. K., ed. Perspectives in plant cell and tissue culture. Int. Rev. Cytol. Suppl. 11B. New York: Academic Press; 1980:209-240.

Raghavan, V. The applications of embryo rescue in agriculture In: Biotechnology in international agricultural research. Los Banos: International Rice Research Institute; 1985:189-197.

Raghavan, V. Embryogenesis in angiosperms. A developmental and experimental study. New York: Cambridge University Press; 1986a:103-111.

Raghavan, V. Variability through wide crosses and embryo rescue. In: Vasil, I. K., ed. Cell culture and somatic cell genetics of plants, vol. 3. Plant regeneration and genetic variability. Orlando, FL: Academic Press; 1986b:613-633.

Raghavan, V. Embryo culture: methods and applications. In: Prakash, J.; Pierik, R. L. M., eds. Plant biotechnology: commercial prospects and problems. New Delhi: Oxford and IBH Publishing; 1993:143-168.

Raghavan, V. In vitro methods for the control of fertilization and embryo development. In: Vasil, I. K.; Thorpe, T. A., eds. Plant cell and tissue culture. Dordrecht: Kluwer Academic Publishers; 1994:173-194.

Raghavan, V. Molecular embryology of flowering plants. New York: Cambridge University Press; 1997:386-389.

Raghavan, V.; Srivastava, P. S. Embryo culture. In: Johri, B. M., ed. Experimental embryology of vascular plants. Berlin: SpringerVerlag; 1982:195-230.

Raghavan, V.; Torrey, J. G. Growth and morphogenesis of globular and older embryos of Capsella in culture. Am. J. Bot. 50:540-551; 1963.
Randoph, L. F. Embryo culture of Iris seed. Bull. Am. Iris Soc. 97:33-45; 1945.

Rappaport, J. In vitro culture of plant embryos and factors controlling their growth. Bot. Rev. 20:201-225; 1954.

Rietsema, J.; Satina, S.; Blakeslee, A. F. The effect of sucrose on the growth of Datura stramonium embryos in vitro. Am. J. Bot. 40:538-545; 1953.

Rijven, A. H. G. C. In vitro studies on the embryo of Capsella bursa-pastoris. Acta Bot. Neerl. 1:157-200; 1952.

Rijven, A. H. G. C. Glutamine and asparagines as nitrogen sources for the growth of plant embryos in vitro: a comparative study of 12 species. Austr. J. Biol. Sci. 9:511-527; 1956.

Ryczkowski, M. Changes of the osmotic value during the development of the ovule. Planta 55:343-356; 1960.

Sanders, M. E.; Burkholder, P. R. Influence of amino acids on growth of Datura embryos in culture. Proc. Natl Acad. Sci. USA 34:516-526; 1948

Sanders, M. E.; Ziebur, N. K. Artificial culture of embryos. In: Maheshwari, P., ed. Recent advances in the embryology of angiosperms. Delhi: International Society of Plant Morphologists; 1963:297-325.

Stefaniak, B. The in vitro development of isolated rye proembryos. Acta Soc. Bot. Polon. 56:37-42; 1987.

Tukey, H. B. Artificial culture of sweet cherry embryos. J. Hered. 24:7-12; 1933.

van Overbeek, J.; Conklin, M. E.; Blakeslee, A. F. Cultivation in vitro of small Datura embryos. Am. J. Bot. 29:472-477; 1942.

van Overbeek, J.; Siu, R.; Haagen-Smith, A. J. Factors affecting the growth of Datura embryos in vitro. Am. J. Bot. 31:219-224; 1944.

Williams, E. G. Interspecific hybridization in pasture legumes. Plant Breed. Rev. 5:237-305; 1987.

Williams, E. G.; Maheswaran, G.; Hutchinson, J. F. Embryo and ovule culture in crop improvement. Plant Breed. Rev. 5:181-236; 1987.

Yeung, E. C.; Sussex, I. M. Embryogeny of Phaseolus coccineus: the suspensor and the growth of the embryo-proper in vitro. Z. Pflanzenphysiol. 91:423-433; 1979.

Ziebur, N. K.; Brink, R. A.; Graf, L. H.; Stahmann, M. A. The effect of casein hydrolysate on the growth in vitro of immature Hordeum embryos. Am. J. Bot. 37:144-148; 1950. 